\title{
农业干旱与气象干旱关联性 一以淮河蛘埠闸以上地区为例
}

\author{
罗 纲 ${ }^{1}$, 阮 甜 ${ }^{2}$, 陈 财 ${ }^{1}$, 高 超 ${ }^{1}$, 李 鹏 $^{3}$, \\ 马松根 ${ }^{3}$, 李贺丽 ${ }^{3}$, 王 欢 ${ }^{3}$
}

(1. 宁波大学地理与空间信息技术系, 宁波 $315211 ; 2$. 安徽师范大学地理与旅游学院, 芜湖 241000 ; 3. 河南省驻马店水文水资源勘测局, 驻马店 450003)

\begin{abstract}
摘要：基于淮河蚌埠闸以上地区 60 个站点 1961-2015 年气象数据, 计算作物水分亏缺指数 (Crop Water Deficit Index, $C W D I$ ) 与相对湿润度指数 (Relative Moisture Index, $M$ ), 以冬小麦干 旱作为农业干旱的代表, 分析生育期内冬小麦干旱与气象干旱时空特征, 并通过游程理论识别 30 场主要干旱事件的历时、烈度及重现期频率, 展开农业干旱与气象干旱关联性研究, 结果表 明: (1) 时间上, 冬小麦生育期内农业干旱旱情年占比均高于气象干旱, 年际差最多年份均发生 在冬前生长期; (2) 空间上, 全生育期和各个生育期内的冬小麦干旱和气象干旱呈纬向分布, 由 南至北旱情逐渐加重, 冬小麦干旱 $75 \%$ 以上中旱占比发生在越冬期至灌浆成熟期, 气象干旱仅 在越冬期出现; (3) 冬小麦干旱相较气象干旱存在延时, 且烈度大于气象干旱, 平均历时分别为 18.8 旬和 17.3 旬, 平均烈度分别为 12.2 和 9.9 ; (4)气象干旱历时达到 1.28 旬或干旱烈度达到 3.35 时, 便会引发冬小麦干旱, 且冬小麦干旱历时、烈度重现期频率大于气象干旱, 农业干旱较 气象干旱持续周期更长、频率及强度更大,气象干旱加剧农业干旱旱情。
\end{abstract}

关键词: 农业干旱;气象干旱; 游程理论; 重现期

干旱的频繁发生和广范围影响，已经威胁着全球社会经济发展和人类的福祉健康水 平，是不可忽视的问题 ${ }^{[1,2]}$ 。国际通行标准是将干旱类型划分为气象、农业、水文和社会 经济四大干旱类别 ${ }^{[3]}$, 然而气象干旱与农业干旱又是最受学者关注的两大干旱类别 ${ }^{[4]}$ 。

农业干旱中的本质是由于作物生育期内的水分供需不平衡引起的，而气象干旱则是 因一定时期内降水量的时空分布不均衡导致的，也会对农业干旱的发生产生影响 ${ }^{\left[{ }^{5}\right]}$ 。然而 干旱的发生是一个缓慢且经历一段时间累积的过程，涉及的影响因素包含气象、农业、 地质、地貌以及人类活动等方面。相关学者分别探究农业干旱和气象干旱特征，多从以 下几个方面展开：（1）运用降水距平百分率 ${ }^{[6,7]}$ 、 $\mathrm{Z}$ 指数 ${ }^{[8]}$ 、土壤湿度干旱指数法 ${ }^{[9]}$ 以及标 准化降水指数（Standardized Precipitation Index, SPI） ${ }^{[10,11]}$ 和标准化降水蒸散指数（Standardized Precipitation Evapotranspiration Index, SPEI） ${ }^{[12-14]}$ 等指标表征气象干旱；（2）基

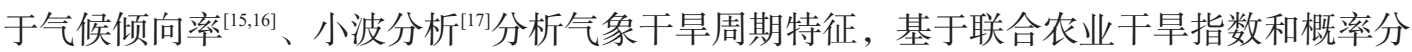
布 ${ }^{[18]}$ 分析农业干旱发生的概率特征; (3) 利用气象资料分析, 研究农业干旱的旱涝时空 演变特征 ${ }^{[19]}$ 、旱涝灾害气候阈值 ${ }^{[20]}$ 、指标适用性评价 ${ }^{[21]}$ 、灾害与产量的定量关系 ${ }^{[2]}$ 等方

收稿日期：2019-05-20；修订日期：2019-07-18

基金项目：国家自然科学基金项目（41871024）

作者简介：罗纲（1993-), 男, 湖北阳新人, 硕士, 研究方向为气候变化与水文水资源。E-mail: 1gsj0808@163.com 通讯作者：高超（1978- ), 男, 安徽全椒人, 博士，教授，研究方向为气候变化与水文水资源。

E-mail: gaoqinchao1@163.com 
面, 判别气象干旱对农业干旱的影响。以上研究多以某一干旱指标来判别干旱发生特 征, 需要建立在特定的时间和空间范围内, 分析对应时空尺度的农业干旱或气象干旱, 但无法关联和分析不同干旱类型之间的时空关系。气象干旱作为其他三种干旱类型的源 头，是干旱灾害发生链的关键诱因。因此，农业干旱与气象干旱等干旱类型之间的关联 性研究逐渐引起学者们的关注。

本研究为了探明农业干旱与气象干旱的关联性特征，收集淮河蛙埠闸地区 60 个站点 的气象资料, 时间跨度为 1961-2015 年，计算旬作物水分亏缺指数（Crop Water Deficit Index, CWDI）和相对湿润度指数（Relative Moisture Index, M), 判别冬小麦干早和气 象干旱等级, 利用游程理论来判别中旱以上等级事件, 计算干旱事件的干旱历时和干旱 烈度，通过 P-III型频率曲线计算干早历时和干旱烈度的重现期，以期未来对淮河蚌埠闸 以上地区农业可持续发展、干旱监测、预警和减灾防灾提供数据支撑。

\section{1 研究方法与数据来源}

\section{1 研究区概况}

淮河蚌埠闸以上地区（图 1)，地 处中国重要的气候过渡地带。截至 2015 年, 该区域多年均气温约 $13.2{ }^{\circ} \mathrm{C}$, 平均降水量约 $900 \mathrm{~mm}$, 时间上降水年际 和年内变化幅度较大, 空间上则表现为 南高北低, 因此相关研究者将其描述为 “强降水洪、有降水涝、无降水旱” 的典 型特征 ${ }^{[23,24]}$ 。作为冬小麦种植区域, 也是 农业旱涝研究的典型区域, 1949-2015年 约 4 年发生一次干早。

\section{2 数据来源}

蛙埠闸以上地区 1961-2015年的 60 个气象站点逐日数据, 其中包括最高

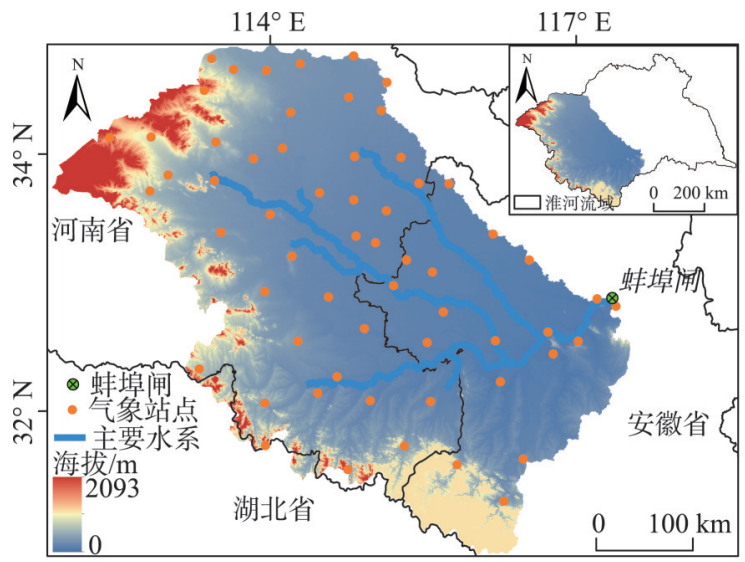

注: 本图基于国家测绘地理信息局标准地图服务网站下 载的审图号为 GS(2016)1603 号标准地图制作, 底图无修改, 下同。

图 1 研究区地理位置

Fig. 1 Geographical location map of the study area 气温、最低气温等 9 个指标类, 用于计算气象干早和冬小麦干早, 以上数据均来自中国 气象局国家气象服务中心; 查阅《中国气象灾害大典》和《中国气象灾害年鉴》[25-27]，提 供有记录以来历史灾情数据; 采用中国科学院地理空间数据云网站（http://www.gscloud. $\mathrm{cn} /$ ) 提供的 $30 \mathrm{~m}$ 分辨率（SRTM数据）地理数据。

\section{3 研究方法}

\subsection{1 $C W D I$ 指数与 $M$ 指数}

计算作物的缺水量与需水量比值得到农作物水分亏缺指数 $(C W D I)$, 是气象行业规 定衡量 “小麦干旱灾害等级” 的重要标准 ${ }^{[28]}$, 相对湿润度指数 $(M)$ 作为多要素综合干 旱指标, 主要依靠区域降水量和蒸发量的关系来衡量气象干早, 是国家 GB/T20481-2006 《气象干旱等级》推荐使用的指标 ${ }^{[29]}$ 。CWDI指数与 $M$ 指数均以旬为时间单位, 计算各个 生育期（冬前生长期：10月下旬至 12 月中旬; 越冬期：12月下旬至 2 月上旬; 返青抽穗 期：2 月中旬至 4 月中旬；灌浆成熟期：4月下旬至 5 月下旬）的 $C W D I$ 和 $M$ 指数表征冬 小麦干旱和气象干旱 ${ }^{[3]}$, 相关公式如下: 


$$
\begin{gathered}
C W D I=a \times C W D I_{i}+b \times C W D I_{i-1}+c \times C W D I_{i-2}+d \times C W D I_{i-3}+e \times C W D I_{i-4} \\
C W D I_{i}=\left\{\begin{array}{cc}
\left(1-\frac{P}{E T_{m i}}\right) \times 100 \% & \left(P \leqslant E T_{m i}\right) \\
0 & \left(P>E T_{m i}\right)
\end{array}\right. \\
E T_{m i}=K c \times E T_{0}
\end{gathered}
$$

式中： $C W D I$ 表示农作物水分亏缺指数; $M$ 表示相对湿润度指数, 可以被用作计算降水 与蒸发的关系，积极表征作物生长期的水分供给状态；其中 $P$ 则是该时期内的累计降水 量; 与此同时需要确定不同生育期的水分亏缺指数权重系数 $(a=0.3 ; b=0.25 ; c=0.2 ; d=$ $0.15 ; e=0.1) ; E T_{m i}$ 为作物某十天的需水量; $K c$ 为作物系数, 安徽省及河南省冬小麦的各 月 $K c$ 值参照国家冬小麦干旱等级划分标准 ${ }^{[30]} ; E T_{0}$ 代表旬参考作物蒸散量 $(\mathrm{mm})$ ，根据 FAO 推荐的彭曼公式得出 ${ }^{[11]}$ 。

\subsection{2 干旱事件识别}

基于游程理论 ${ }^{[32]}$, 采用多阈值法识别干旱事件，计算干旱历时和干旱烈度等特征指 标 ${ }^{[33]}$ 。干旱历时以旬为时间单位，干旱烈度则是干旱事件 $C W D I$ 或 $M$ 的指数累加。图 2 中, $Y_{2} 、 Y_{1} 、 Y_{0}$ 作为区分强烈 干旱指数 度、轻烈度以及合并干旱事件 阈值。识别过程 ${ }^{[34]}$ : 干旱指数值 持续小于 $Y_{2}$ (图 2: a 时段), 则 为一场干旱事件; 干旱指数值 小于 $Y_{1}$ 且大于 $Y_{2}$ 阈值（图 2: b 时段), 连续时间超过 1 旬则为 一场干旱事件, 图 2 中 d 时段 则不属于干旱事件; 若已判定

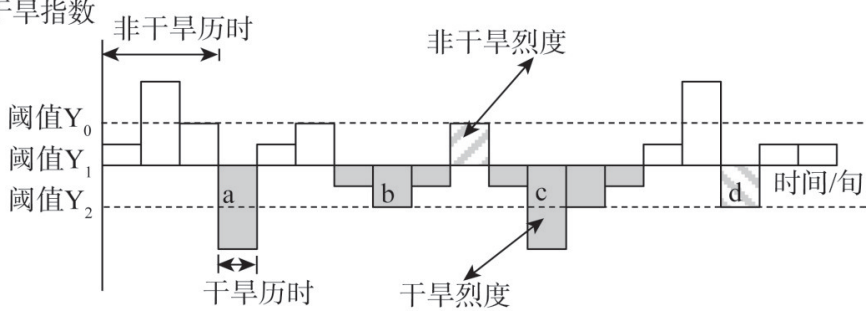

图 2 干早事件识别过程

Fig. 2 Drought event identification process 的两场干旱事件的时间差不足 1 旬，且该时期内干旱指数小于阈值 $Y_{0}$ （图 2: b 时段、c 时段）则可以合并一场干旱事件。根据表 1 中等级划分标准, $C W D I$ 与 $M$ 指数 $\mathrm{Y}_{0}$ 國值采 取试错法并结合专家意见，采取 $C W D I$ 与 $M$ 指数干旱等级指数差值作为 $\mathrm{Y}_{0}$ 阈值的确定， 其中 $\mathrm{Y}_{1} 、 \mathrm{Y}_{2}$ 阈值基于表 1 中 $C W D I$ 与 $M$ 指数干旱等级选取，查阅《中国气象灾害大典》 (河南卷、安徽卷) 历史资料，结合实际干旱事件，最终确定 $C W D I$ 与 $M$ 指数阈值: $\mathrm{Y}_{0}$ 干旱

\begin{tabular}{|c|c|c|c|c|}
\hline \multirow{2}{*}{ 等级 } & \multirow{2}{*}{ 类型 } & \multicolumn{2}{|c|}{ 作物水分亏缺指数 $C W D I / \%$} & \multirow{2}{*}{$\begin{array}{c}\text { 相对湿润度指数 } M \\
\text { 全生育期 }\end{array}$} \\
\hline & & 返青抽穗期 & 其余发育期 & \\
\hline 0 & 无旱 & $C W D I \leqslant 30$ & $C W D I \leqslant 35$ & $-0.40<M$ \\
\hline 1 & 轻旱 & $30<C W D I \leqslant 40$ & $35<C W D I \leqslant 50$ & $-0.65<M \leqslant-0.40$ \\
\hline 2 & 中旱 & $40<C W D I \leqslant 50$ & $50<C W D I \leqslant 65$ & $-0.80<M \leqslant-0.65$ \\
\hline 3 & 重旱 & $50<C W D I \leqslant 60$ & $65<C W D I \leqslant 80$ & $-0.95<M \leqslant-0.80$ \\
\hline 4 & 特旱 & $C W D I>60$ & $C W D I>80$ & $M \leqslant-0.95$ \\
\hline
\end{tabular}
阈值分别为 $20 \%$ 与 $-0.15 ; \mathrm{Y}_{1}$ 干早阈值分别为 $35 \%$ 与 $-0.4 ; \mathrm{Y}_{2}$ 干早阈值分别为 $50 \%$ 与 -0.65 。

\section{表 1 作物 $C W D I$ 指数与 $M$ 指数干旱分级}

Table 1 The crop water deficit index $(C W D I)$ and relative moisture $(M)$ index drought classification 


\section{2 结果分析}

\section{1 冬小麦干旱与气象干旱的时空特征}

\section{1 .1 冬小麦干早与气象干旱年际变化}

相关研究表明 ${ }^{[35]}$ ，中旱以上等级旱情会对农业产量产生不利影响。1961-2015 年淮河 蛙埠闸以上地区 60 个站点 $C W D I$ 和 $M$ 指数的均值，根据分位数模型分别选择 0.25 分位点 和 0.75 分位点数值 ${ }^{[36]}$, 对年际与年内旱情进行分析。全生育期（图 3) CWDI 指数均值均 未出现特旱等级, $82 \%$ 的年份出现中旱以上旱情, 年内 0.25 分位点数值与 0.75 分位点数 值差值变化幅度小; $M$ 指数均值全生育期内仅出现 1 次中旱旱情，但 0.25 分位点数值 $30 \%$ 的年份出现中早以上等级旱情。

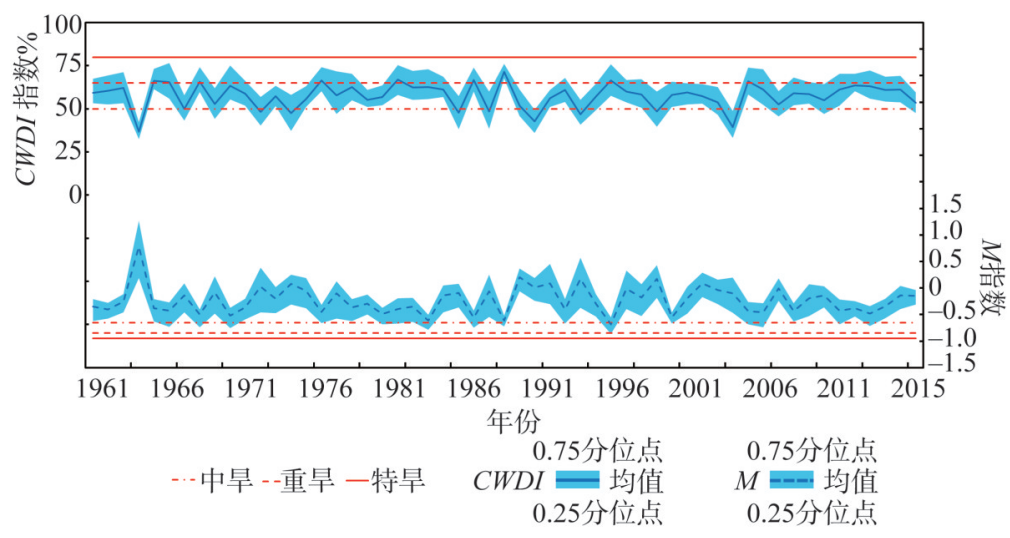

图 3 1961-2015 冬小麦全生育期 $C W D I$ 指数与 $M$ 指数均值年际变化

Fig. 3 Interannual variation of $C W D I$ and $M$ mean values in the whole growth period from 1961 to 2015

分析 1961-2015 年 $C W D I$ 与 $M$ 指数各生育期 60 个站点均值旱情年占比（中早以上): 冬前生长期（图 4a）, $C W D I$ 旱情年占比为 $64 \%$, 较 $M$ 高出 $29 \%$; 越冬期（图 $4 \mathrm{~b}$ ), $C W D I$ 旱情年占比为 $85 \%$, 而 $M$ 为 $29 \%$; 返青抽穗期（图 4c ）, 由于其水分临界值与其他生育期 不同， $C W D I$ 旱情年占比为 $80 \%$ ，其中特旱占比达 $35 \%, M$ 旱情年占比为 $16 \%$; 灌浆成熟 期（图 4d），CWDI 占比为 $73 \%$ ，但特旱仅占 $4 \%, M$ 旱情年占比为 $9 \%$ 。

$C W D I$ 与 $M$ 中旱与特旱的指数差分别为 $30 \%$ 和 0.25 , 利用指数差来判别年际变化与年 内变化, 其中 $C W D I$ 下 0.75 ( $M$ 为 0.25 ) 分位点数值年际差值大于指数差的定义为年际 差，年内 0.25 到 0.75 分位点数值差值大于指数差则定义为年内差。 $C W D I$ 年际差，最多 年份占比出现在冬前生长期，占统计年份的 $13 \%$ ，而最大年际差在返青抽穗期，达到 $46 \% ; M$ 年际差最多年份也出现在冬前生长期，年份占比为 $16 \%$, 但最大年际差在越冬 期，达到 1.97。CWDI 年内差最多年份在灌浆成熟期，共有 4 年; $M$ 年内差在越冬期、返 青抽穗期与灌浆成熟期各有 1 年。

为检验 1961-2015 年冬小麦生育期的 $C W D I$ 各站点旱情一致性，60个站点 $C W D I$ 均值 与 0.75 分位点数值都达到特旱等级定义为特旱一致年，而均值与 0.25 分位点数值都达到 无旱等级的定义为无旱一致年, 旱情年占比是指出现中旱及以上等级的年份占比。就 $C W D I$ 来看 (表 2)：无旱一致年在冬前期占比最大，为 $38 \%$; 特旱一致年在返青抽穗期 

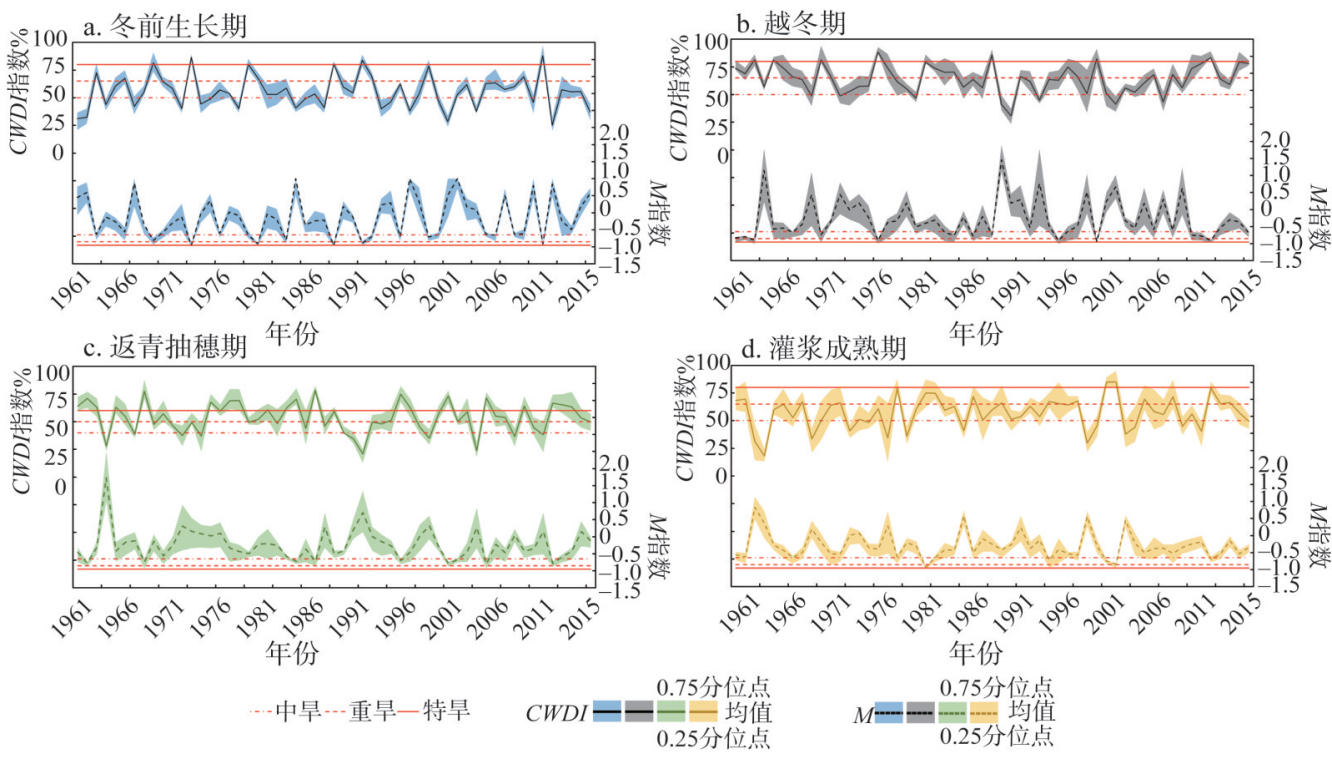

年份

图 4 1961-2015 冬小麦生育期 $C W D I$ 指数与 $M$ 指数均值年际变化

Fig. 4 Interannual variation of $C W D I$ and $M$ mean value in the growth period of winter wheat from 1961 to 2015

表 2 冬小麦生育期 $C W D I$ 指数与 $M$ 指数旱情一致性对比

Table 2 Comparison of the consistency between $C W D I$ and $M$ indexes in the growth period of winter wheat

\begin{tabular}{clcccc}
\hline 指数 & 占比 & 冬前生长期 & 越冬期 & 返青抽穗期 & 灌浆成熟期 \\
\hline \multirow{2}{*}{$C W D I$} & 特旱一致年 & 11 & 15 & 35 & 4 \\
& 无早一致年 & 38 & 16 & 20 & 27 \\
& 旱情年 & 53 & 80 & 76 & 67 \\
& 特早一致年 & 4 & 0 & 0 & 0 \\
$M$ & 无早一致年 & 51 & 35 & 46 & 44 \\
& 早情年 & 38 & 58 & 44 & 47 \\
\hline
\end{tabular}

占比最大，为 $35 \%$; 旱情年在越冬期占比最高，且高达 $80 \%$ 。

由于 $M$ 指数值与干旱等级成反比, 60 个站点 $M$ 均值与 0.25 分位点数值都达到特旱等 级定义为特旱一致年, 而 $M$ 均值与 0.75 分位点数值都达到无旱等级的定义为无旱一致 年。特旱一致年与无旱一致年最大占比均出现冬前生长期，分别为 $4 \%$ 和 $51 \%$ 。冬前生长 期旱情较轻，而越冬期旱情年占比最大，这与地区实际降水时间分布一致。

\section{1 .2 冬小麦干旱与气象干旱空间分布}

基于 $C W D I$ 和 $M$ 指数，在 ArcGIS 10.3 软件中使用 IDW 插值法，对生育期内冬小麦干 旱与气象干旱达到中旱以上等级占比采取空间插值，并进行 M-K（Mann-Kendall）趋势 性检验。

对比冬小麦干旱与气象干旱全生育期中旱以上等级占比的空间表现为北部区域高 中旱占比区域多于南部，基本呈纬向分布。冬小麦干旱中旱以上占比来看，61\% 75\% 占比区域面积最大, 小于 $45 \%$ 占比最少, 北部区域占比达到 $76 \%$ 以上; 气象干旱在全 生育期内中旱以上占比主要在 $45 \%$ $60 \%$, 空间范围较冬小麦干旱进一步扩大，在生育 期内均未出现 $75 \%$ 中旱以上占比, 各站点 $C W D I$ 指数达到中旱以上等级的占比明显高于 
$M$ 指数，区域内冬小麦干旱较气象干 旱更为严重。

各生育期冬小麦干早（图 6a～图 6d）与气象干早（图 6e 图 6h）的空 间分布趋势基本一致。就冬小麦冬前 生长期而言（图 6a），呈现下降趋势 的站点约 $60 \%$ ，其中流域北部是早情 较重区域; 越冬期（图6b）呈现出较 明显的湿润化趋势，已有约 $80 \%$ 的站 点呈现下降趋势，即使南部和北部有 a. $C W D$

a. $C W D I$

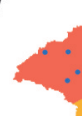

中旱以上占比\%

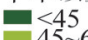

$45 \sim 60$

$61 \sim 75$
$-76 \sim 90$

- 气象观测站 b. $M$

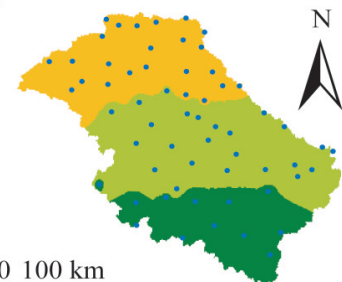

图 5 冬小麦全生育期 $C W D I$ 指数和 $M$ 指数 中旱以上等级占比空间分布

Fig. 5 Spatial distribution of $C W D I$ and $M$ indexes above moderate drought level in the whole growth period of winter wheat 部分站点上升; 返青抽穗期（图 6c ），由于出现下降的站点减少至约 $72 \%$ ，而旱情开始呈 现上升也主要分布在北部及南部，干旱化较为明显。对于冬前生长期、越冬期及返青抽 穗期 3 个生育期，冬小麦没有十分显著的干湿变化。在灌浆成熟期冬小麦干旱处于上升

a. 冬前生长期 $C W D I$

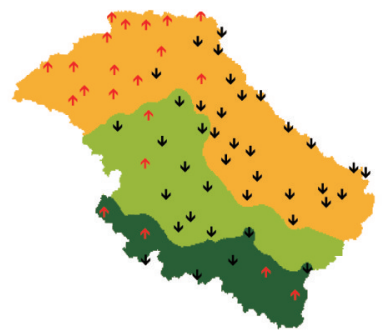

d. 灌浆成熟期 $C W D I$

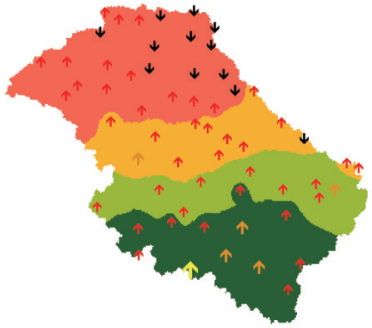

g. 返青抽穗期 $M$

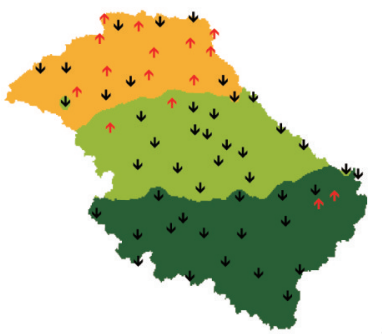

$\Downarrow$ 下降趋势 (通过 0.05 显著性检验)

$\Downarrow$ 下降趋势 (通过0.1显著性检验)

$\uparrow$ 上升趋势 (通过0.1显著性检验) b. 越冬期 $C W D I$

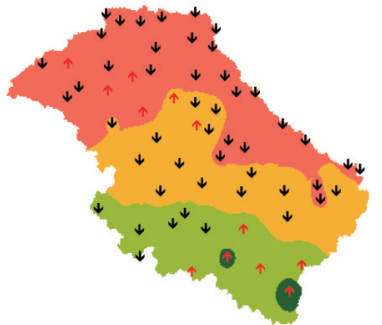

e. 冬前生长期 $M$

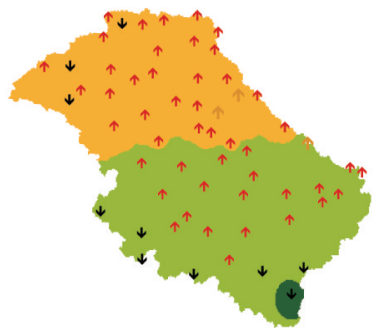

h. 灌浆成熟期 $M$

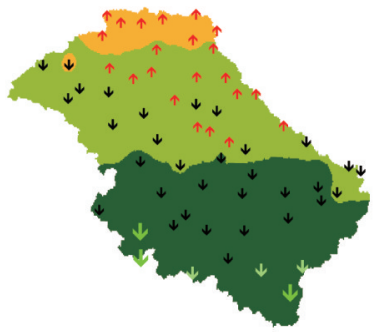

c. 返青抽穗期 $C W D I$

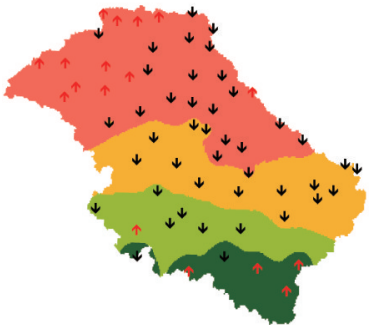

f. 越冬期 $M$

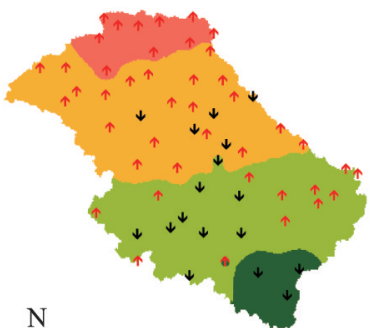

$N$

中早以上占比 $/ \%$

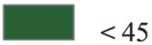

$45 \sim 60$

$\square 1 \sim 75$

$76 \sim 90$

$0100 \mathrm{~km}$

图 6 冬小麦生育期各站点 $C W D I$ 指数和 $M$ 指数中旱等级占比及 $\mathrm{M}-\mathrm{K}$ 趋势检验空间分布

Fig. 6 Spatial distribution of $C W D I$ and $M$ indexes in the above moderate drought level and M-K trend test 
趋势，有 $10 \%$ 的站点通过 0.1 显著性检验，灌浆成熟期地区干早化趋势较明显。

冬前生长期（图 6e）约 83\%的站点呈上升趋势，气象干旱有干旱的趋势，但通过 0.1 显著性检验的站点仅占 5\% ; 越冬期（图 6f）约 72\%的站点呈上升趋势，此时北部的站点 旱情出现上升, 旱情加重, 南部旱站点旱情趋势下降, 旱情减轻; 返青抽穗期（图 $6 \mathrm{~g}$ ) 呈现上升趋势的站点主要分布在北部地区，下降趋势站点中均未通过 0.1 显著性检验; 灌 浆成熟期（图6h）气象干旱开始加剧，呈现下降趋势的站点中，仅有 $13 \%$ 的站点通过 0.1 显著性检验。

\section{2 农业干旱与气象干旱关联性研究}

\subsection{1 干早事件识别}

关于农业干旱与气象干旱之间存在着怎样的关联，则需要通过游程理论判别淮河蚌埠 闸以上地区 1961-2015 年发生的冬小麦干旱和气象干旱，查阅相关历史文资料 ${ }^{[25-27]}$, 对比验 证历史时期的干旱程度和干旱事件，共识别30场典型干旱事件（表3）。

序号 4 6 和 10 11 对应时段冬小麦干早历时都达到了 27 旬，即整个识别时段内都发 生干旱, 覆盖了冬小麦的全生育期, 同期的气象干旱也都分别达到 19旬以上, 基本覆盖 了冬小麦的全生育期。通过识别干旱历时，除序号 4 和 21 干旱事件，统计剩余年份冬小 麦干早历时和干早烈度, 都高于同期的气象干早, 因此冬小麦干早周期更长, 强度更 大。 30 场干旱事件中, 冬小麦干旱和气象干旱平均历时分别为 18.8 旬和 17.3 旬, 平均烈 度分别为 12.2 和 9.9 , 其中序号 $3 、 14 、 16 、 17 、 25$ 和 28 干早事件的冬小麦干早历时与气 象干旱历时一致，其中 3 和 28 号干旱事件的各自干旱历时与烈度更是一致。

统计历史时期内干旱事件的干旱历时和烈度（表3)，定量确定冬小麦干旱与气象干 旱的关系, 通过 OriginPro 9.0 软件中拟合函数中的 Logarithm 三参数对数函数 ${ }^{[37]}$, 对表 3 中 1 20 号干旱事件建模，21 30 号干旱事件用于检验。基于模型基本形式 [式（5）]，推 导可得干旱历时和干旱烈度的公式 [式 (6)、式 (7) ], 并在图 7 中表示。可知, 气象干 旱历时达到 1.28 旬, 或者干旱烈度达 3.35 , 此时会发生冬小麦干旱。

$$
\begin{gathered}
Y=a+b \times \ln (X+c) \\
Y_{C-D}=-19.1579+12.48588 \times \ln \left(X_{M-D}+3.35587\right) \\
Y_{C-I}=-88.46045+31.54314 \times \ln \left(X_{M-I}+13.16657\right)
\end{gathered}
$$

式中: $Y$ 是冬小麦干旱 $(C W D I)$ 历时或烈度; $X$ 是气象干旱 $(M)$ 历时或烈度; $a$ 和 $b$ 是 模型函数常数; $Y_{C-D}$ 表示 $C W D I$ 干旱历时 (旬); $X_{M-D}$ 表示 $M$ 干旱历时 (旬)； $Y_{C-I}$ 表 示 $C W D I$ 干旱烈度; $X_{M-I}$ 表示 $M$ 干旱烈度。

表 3 后 10 场干旱事件的干旱历时和干旱烈度代人函数中，模拟冬小麦干旱历时和干 旱烈度值（表 4)。验证气象干旱条件下冬小麦干旱模拟值与实测值，除第 21 场干旱的历 时、烈度及第 23 场干旱烈度相对误差较大，其余模拟与实测值误差均低于 $30 \%$ ，冬小麦 干旱和气象干旱在三参数对数函数模型历时及烈度的模拟效果好, 可得农业干旱气象干 旱的的定量关系及其关联度。

\subsection{2 干早烈度与干早历时频率}

基于 $C W D I$ 和 $M$ 下 30 场干旱事件的干旱历时及烈度, 本研究采用相关学者研究方 法 $^{[38]}$ 进行参数估计和适线调整, 通过目估适线法调整干早历时和干旱烈度特征变量分布 函数, 计算获得重现期平均值 $E X$, 离差系数 $C_{V}$ 、变差系数 $C_{S}$, 选取重现期 $200 \mathrm{a} 、 100 \mathrm{a} 、$ 
表 31961 -2015 年冬小麦干旱与气象干旱事件

Table 3 Winter wheat drought and meteorological drought events in 1961-2015

\begin{tabular}{|c|c|c|c|c|c|c|}
\hline \multirow{2}{*}{ 序号 } & \multicolumn{3}{|c|}{ 冬小麦干旱 $C W D I$} & \multicolumn{3}{|c|}{ 气象干旱 $M$} \\
\hline & 起始时间/(年/月/旬) & 历时/旬 & 烈度 & 起始时间/(年/月/旬) & 历时/旬 & 烈度 \\
\hline 1 & 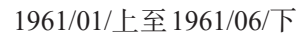 & 18 & 12 & 1961/01/上至 1961/06/中 & 17 & 10 \\
\hline 2 & 1961/12/上至 $1962 / 06 /$ 中 & 20 & 13 & 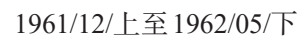 & 18 & 12 \\
\hline 3 & $1962 / 12 /$ 上至 $1963 / 03 /$ 上 & 11 & 7 & $1962 / 12 /$ 上至 $1963 / 03 /$ 上 & 11 & 7 \\
\hline 4 & 1964/11/中至1965/06/下 & 23 & 15 & 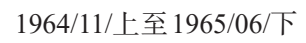 & 24 & 12 \\
\hline 5 & 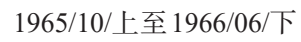 & 27 & 17 & 1965/10/上至 $1966 / 06 /$ 中 & 25 & 10 \\
\hline 6 & 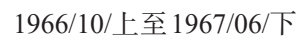 & 27 & 16 & 1966/10/上至 $1967 / 06 /$ 中 & 26 & 11 \\
\hline 7 & 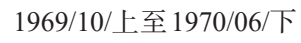 & 27 & 18 & $1969 / 10 /$ 上至 $1970 / 04 /$ 上 & 19 & 9 \\
\hline 8 & 1975/01/上至 $1975 / 06 /$ 下 & 18 & 11 & 1975/01/上至 1975/06/中 & 17 & 6 \\
\hline 9 & 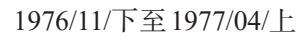 & 14 & 10 & 1976/11/下至 $1977 / 03 /$ 上 & 11 & 9 \\
\hline 10 & 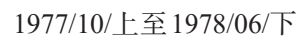 & 27 & 16 & 1977/10/中至 1978/06/中 & 25 & 10 \\
\hline 11 & 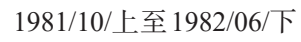 & 27 & 16 & 1981/10/中至 1982/06/下 & 26 & 10 \\
\hline 12 & 1982/10/中至 1983/06/中 & 25 & 15 & 1982/10/中至 $1983 / 06 /$ 上 & 24 & 12 \\
\hline 13 & 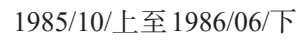 & 27 & 17 & $1985 / 11 /$ 上至 $1986 / 06 /$ 上 & 22 & 14 \\
\hline 14 & 1987/12/中至 1988/06/下 & 20 & 13 & 1987/12/中至1988/06/下 & 20 & 10 \\
\hline 15 & $1990 / 10 /$ 上至 $1991 / 02 /$ 上 & 13 & 7 & 1990/10/上至 1991/01/中 & 11 & 5 \\
\hline 16 & 1991/10/中至 $1992 / 03 /$ 上 & 15 & 11 & 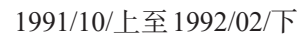 & 15 & 8 \\
\hline 17 & 1994/03/下至 1994/06/下 & 10 & 6 & 1994/03/中至 1994/06/中 & 10 & 4 \\
\hline 18 & 1995/01/中至 1995/06/下 & 17 & 11 & 1995/01/上至 $1995 / 06 /$ 上 & 16 & 11 \\
\hline 19 & 1995/11/中至 1996/06/中 & 22 & 14 & 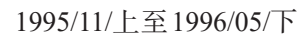 & 21 & 13 \\
\hline 20 & 1996/12/上至 $1997 / 06 /$ 中 & 17 & 11 & 1996/10/中至 1997/06/中 & 12 & 12 \\
\hline 21 & 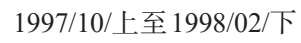 & 9 & 5 & 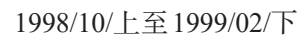 & 15 & 12 \\
\hline 22 & 2000/02/上至2000/06/下 & 15 & 10 & 2000/02/上至 2000/05/下 & 12 & 9 \\
\hline 23 & 2001/03/中至 2001/06/下 & 11 & 8 & 2001/03/上至 $2001 / 06 /$ 上 & 10 & 8 \\
\hline 24 & 2003/12/中至 2004/06/下 & 20 & 12 & 2003/12/中至 2004/05/下 & 17 & 10 \\
\hline 25 & 2005/10/中至 2006/06/下 & 20 & 13 & 2005/10/中至 $2006 / 06 /$ 上 & 25 & 14 \\
\hline 26 & 2008/10/上至 2009/02/中 & 14 & 10 & 2008/10/上至 2009/01/下 & 12 & 9 \\
\hline 27 & 2010/10/上至2011/06/下 & 27 & 21 & 2010/10/上至 $2011 / 06 /$ 上 & 25 & 19 \\
\hline 28 & 2011/12/下至2012/06/下 & 19 & 13 & 2011/12/中至2012/06/中 & 19 & 13 \\
\hline 29 & 2013/02/中至2013/06/下 & 14 & 9 & 2013/02/中至 2013/06/中 & 13 & 7 \\
\hline 30 & 2014/12/上至2015/03/下 & 12 & 8 & 2014/12/上至 $2015 / 03 /$ 上 & 10 & 7 \\
\hline
\end{tabular}
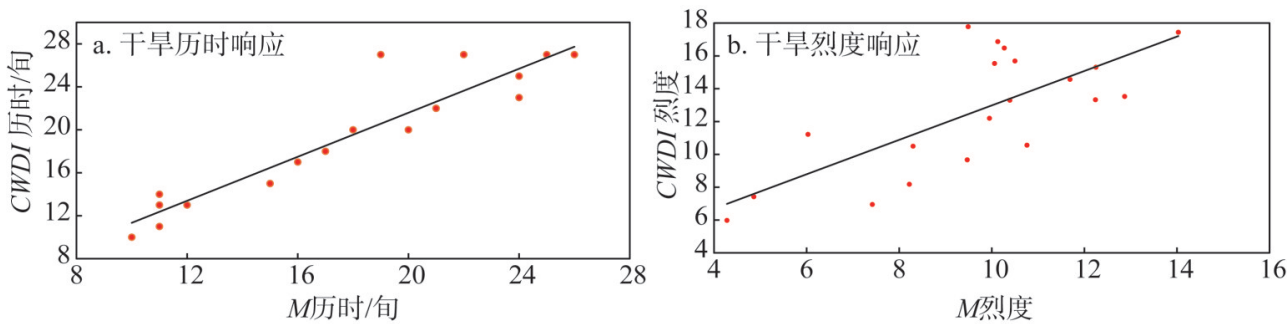

图 7 冬小麦干旱对气象干旱的响应关系

Fig. 7 Response of winter wheat drought to meteorological drought 
表 4 冬小麦干旱事件实际值与模拟值

Table 4 Comparison of measured and simulated values of winter wheat drought events

\begin{tabular}{ccccccccc}
\hline \multirow{2}{*}{ 序号 } & \multicolumn{3}{c}{ 干早历时 } & & \multicolumn{3}{c}{ 干旱烈度 } \\
\cline { 2 - 3 } \cline { 7 - 8 } \cline { 7 - 8 } & 实测值/旬 & 模拟值/旬 & 相对误差/\% & & 实测值 & & 模拟值 & 相对误差/\% \\
\hline 21 & 14 & 16.83 & 20.25 & & 9.5 & 14.70 & 54.69 \\
23 & 15 & 13.28 & 11.45 & & 9.88 & 12.72 & 28.76 \\
24 & 11 & 10.67 & 3.00 & & 8.05 & 11.54 & 43.35 \\
25 & 20 & 19.00 & 5.01 & & 12.17 & 12.94 & 6.35 \\
26 & 17 & 19.00 & 11.76 & & 11 & 12.58 & 14.40 \\
27 & 14 & 13.28 & 5.13 & & 10.02 & 11.84 & 18.12 \\
28 & 27 & 26.42 & 2.15 & & 21.37 & 19.77 & 7.50 \\
29 & 19 & 21.02 & 10.65 & & 13.27 & 15.81 & 19.11 \\
30 & 14 & 14.51 & 3.65 & & 9.22 & 10.49 & 13.80 \\
\hline
\end{tabular}

$50 \mathrm{a} 、 20 \mathrm{a}$ 和 $10 \mathrm{a}$ ，统计干旱历时与干旱烈度各自重现期经验频率点数值与理论频率点数 值的相对误差。 $C W D I$ 指数与 $M$ 指数干旱历时重现期平均相对误差分别为 $3.8 \%$ 和 $4.4 \%$ ，干 早烈度重现期平均相对误差分别为 $8.3 \%$ 和 $10.2 \%$ ，拟合 P- III 型频率曲线（图 $8 \mathrm{a}$ 、图 $8 \mathrm{~b}$ ）, 分析农业干早与气象干早重现期频率。
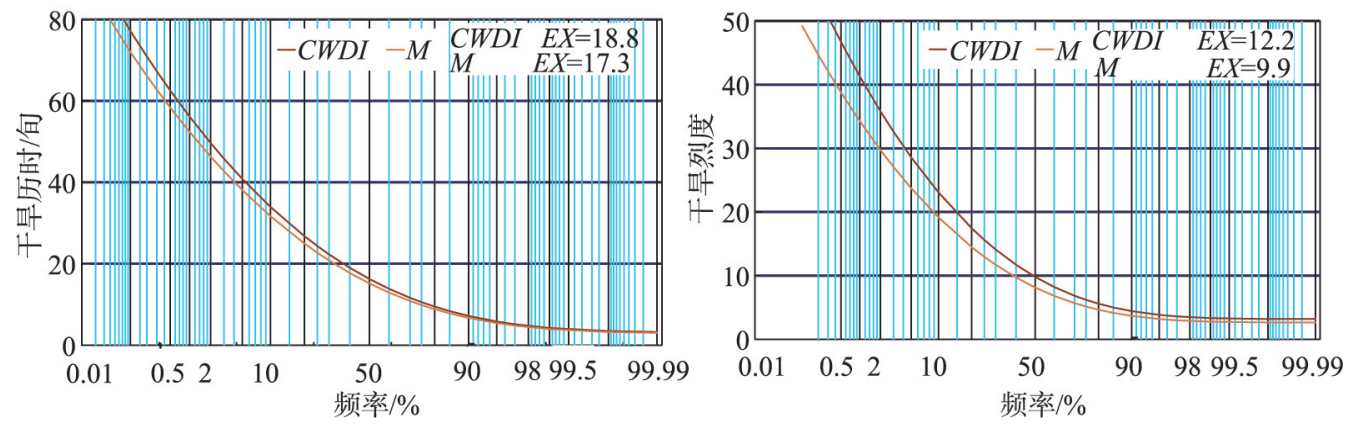

图 8 冬小麦干旱和气象干旱历时及烈度的频指数曲线 ( $E X$ 为均值)

Fig. 8 Frequency curve of winter wheat drought and meteorological drought duration and severity ( $E X$ is the mean value)

$C W D I$ 和 $M$ 干早历时在同一频率下冬小麦干早重现期高于气象干早（图 8a）。冬小麦 干旱与气象干旱历时均值 $E X$ 为 18.8 和 17.3 , 离差系数 $C v$ 为 0.6 , 偏态系数 $C s$ 为 1.44 , 冬 小麦干旱历时重现期 $50 \mathrm{a}(P=2 \%)$ ，此时对应的气象干旱为 $80 \mathrm{a}$ 。因此，冬小麦干旱历 时重现期频率是高于同期气象干旱重现期频率。CWDI 与 $M$ 的干旱烈度重现期相差较大 (图 8b), 冬小麦干旱与气象干旱历时均值 $E X$ 为 12.2 和 9.9 , 离差系数 $C v$ 为 0.68 , 偏态系 数 $C s$ 为 $1.84,50 \mathrm{a}$ 一遇 $(P=2 \%)$ 的冬小麦干旱烈度, 在气象干旱烈度中约 $100 \mathrm{a}$ 一遇。 冬小麦干旱和气象干旱在干旱历时重现期上相差 $60 \%$ ，而干早烈度重现期上相差 $200 \%$ 。

计算 $C W D I$ 和 $M$ 的 30 场干旱事件干旱历时和干旱烈度重现期（表 5), 据相关研究方 法 ${ }^{[39]}$ ，冬小麦干旱重现期 $\left(T_{C}\right)$, 选取冬小麦干旱历时 $\left(T_{C_{-} D}\right)$ 和干旱烈度 $\left(T_{C_{-} S}\right)$ 重现期 的最大值为代表; 对于气象干旱重现期 $\left(T_{M}\right)$ 而言, 重现期选取规则同冬小麦干旱保持 
表 5 基于 $C W D I$ 和 $M$ 的干旱事件重现期

Table 5 Recurrence period of drought events based on $C W D I$ and $M$ indexes

\begin{tabular}{|c|c|c|c|c|c|c|}
\hline \multirow{2}{*}{$\begin{array}{c}\text { 干旱事件 } \\
\text { 序号 }\end{array}$} & \multicolumn{3}{|c|}{ 基于 $C W D I$ 的干早重现期/a } & \multicolumn{3}{|c|}{ 基于 $M$ 的干旱重现期/a } \\
\hline & $\begin{array}{c}\text { 历时 } \\
\text { 重现期 } T_{C S S} \\
\end{array}$ & $\begin{array}{c}\text { 烈度 } \\
\text { 重现期 } T_{C \_D} \\
\end{array}$ & $\begin{array}{c}\text { 冬小麦 } \\
\text { 干旱重现期 } T_{C}\end{array}$ & $\begin{array}{c}\text { 历时 } \\
\text { 重现期 } T_{M_{L} S}\end{array}$ & $\begin{array}{c}\text { 烈度 } \\
\text { 重现期 } T_{M D D}\end{array}$ & $\begin{array}{l}\text { 气象干早 } \\
\text { 重现期 } T_{M}\end{array}$ \\
\hline 1 & 2.1 & 2.2 & 2.2 & 2.2 & 2.1 & 2.2 \\
\hline 2 & 2.8 & 2.8 & 2.8 & 2.4 & 5.2 & 5.2 \\
\hline 3 & 1.1 & 1.1 & 1.1 & 1.2 & 1.2 & 1.2 \\
\hline 4 & 3.4 & 3.9 & 3.9 & 5.2 & 6.2 & 6.2 \\
\hline 5 & 31 & 7.8 & 31 & 10.3 & 2.4 & 10.3 \\
\hline 6 & 31 & 5.2 & 31 & 31 & 3.1 & 31 \\
\hline 7 & 31 & 15.5 & 31 & 2.8 & 1.8 & 2.8 \\
\hline 8 & 2.1 & 1.9 & 2.1 & 2.2 & 1.1 & 2.2 \\
\hline 9 & 1.5 & 1.4 & 1.5 & 1.2 & 1.6 & 1.6 \\
\hline 10 & 31 & 6.2 & 31 & 10.3 & 2.6 & 10.3 \\
\hline 11 & 31 & 4.4 & 31 & 31 & 2.2 & 31 \\
\hline 12 & 3.9 & 3.4 & 3.9 & 5.2 & 4.4 & 5.2 \\
\hline 13 & 31 & 10.3 & 31 & 3.9 & 15.5 & 15.5 \\
\hline 14 & 2.8 & 2.6 & 2.8 & 3.1 & 2.8 & 3.1 \\
\hline 15 & 1.2 & 1.1 & 1.2 & 1.2 & 1.1 & 1.2 \\
\hline 16 & 1.6 & 1.6 & 1.6 & 1.6 & 1.3 & 1.6 \\
\hline 17 & 1.0 & 1.0 & 1.0 & 1.1 & 1.0 & 1.1 \\
\hline 18 & 1.8 & 1.7 & 1.8 & 1.7 & 3.4 & 3.4 \\
\hline 19 & 3.1 & 3.1 & 3.1 & 3.4 & 7.8 & 7.8 \\
\hline 20 & 1.2 & 1.2 & 1.2 & 1.4 & 1.3 & 1.4 \\
\hline 21 & 1.5 & 1.3 & 1.5 & 1.6 & 4.4 & 4.4 \\
\hline 22 & 1.6 & 1.5 & 1.6 & 1.4 & 1.8 & 1.8 \\
\hline 23 & 1.1 & 1.1 & 1.1 & 1.1 & 1.4 & 1.4 \\
\hline 24 & 2.8 & 2.1 & 2.8 & 2.2 & 1.9 & 2.2 \\
\hline 25 & 1.8 & 1.8 & 1.8 & 2.2 & 1.6 & 2.2 \\
\hline 26 & 1.5 & 1.6 & 1.6 & 1.4 & 1.5 & 1.5 \\
\hline 27 & 31 & 31 & 31 & 10.3 & 31 & 31 \\
\hline 28 & 2.2 & 2.4 & 2.4 & 2.8 & 10.3 & 10.3 \\
\hline 29 & 1.5 & 1.3 & 1.5 & 1.5 & 1.2 & 1.5 \\
\hline 30 & 1.1 & 1.2 & 1.2 & 1.1 & 1.1 & 1.1 \\
\hline
\end{tabular}

着一致。冬小麦干旱历时和干旱烈度重现期 5 7号、10 11 号和 13号干旱事件差距较大 外，其余 24 场干旱事件干旱历时与干旱烈度重现期差距均较小，对比冬小麦，气象干旱 中有 7 场干旱事件的历时和烈度重现期误差大。基于干旱事件发生顺序，对比 $T_{C}$ 和 $T_{M}$ 干 旱重现期频率, 进行双变量相关性系数分析 ${ }^{[34]}, T_{C}$ 和 $T_{M}$ 干早事件重现期相关系数达到 0.77 , 通过了 Pearson下 0.01 显著性检验, 而在非参数相关性系数也达到 0.79 和 0.91 , 通 过了 Kendall 和 Spearman 下 0.01 显著性检验，因此 $T_{C}$ 和 $T_{M}$ 干早重现期频率相关性较好。 


\section{3 结论与讨论}

\section{1 结论}

基于 60 个站点的日尺度多要素气象数据, 运用 $C W D I$ 和 $M$ 分别表征冬小麦干早和气 象干旱，对比分析各生育期两种干旱的时空特征；基于游程理论识别主要干旱事件的干 旱烈度和干旱历时，利用P-III型频率曲线得到冬小麦干旱和气象干旱的重现期频率，探 究农业干旱与气象干旱的关联性。主要结论如下:

（1）年际变化: $C W D I$ 均值中旱以上年份占比高于 $M ; C W D I$ 与 $M$ 年际差, 最多年份 占比均出现在冬前期，分别是 $13 \%$ 和 $16 \%, C W D I$ 最大年际差值出现在返青抽穗期，相差 达到 $46 \%$ ，而 $M$ 最大年际差值出现在越冬期，达到 $1.97 ; C W D I$ 特旱一致年返青抽穗期出 现年份次数最多，但最高旱情年占比与 $M$ 保持一致，均出现在越冬期，而各生育期站点 的旱情等级年内变化不明显。

(2) 空间分布：对于冬小麦干旱和气象干旱中早以上等级而言，呈现由南至北逐渐 递加, $C W D I$ 越冬期至灌浆成熟期均出现 $75 \%$ 中旱以上等级占比, 而 $M$ 仅在越冬期出 现，相较于气象干旱，冬小麦干旱更严峻。就冬小麦各个生育期而言，干旱变化趋势并 不十分明显，通过显著性检验的站点较少。

（3）就冬小麦干早而言，其干早历时与烈度值均高于同期气象干旱，平均历时分别 为 18.8 旬和 17.3 旬, 平均烈度分别为 12.2 和 9.9 ; 发生冬小麦干旱，对应气象干旱干旱烈 度达 3.35 , 历时达 1.28 旬。未来的冬小麦干早历时相较于气象干旱更长，且烈度更强。 冬小麦干旱历时与干旱烈度重现期频率高于气象干旱，冬小麦干旱和气象干旱在干旱历 时重现期上相差 60\%，而干旱烈度重现期上相差 200\%，冬小麦干旱与气象干旱重现期频 率相关性达到 0.77 , 通过了显著性检验。因此，农业干旱的发生周期更长，发生频率更 高，面临的农业灾害风险也会不断增加，而气象干旱会加剧农业干旱，农业干旱对气象 干早有一定的滞后性。

\section{2 讨论}

通过计算 $C W D I$ 指数和 $M$ 指数，分析了不同生育期冬小麦干旱和气象干旱的时空特 征及联系，判别历史时期干旱事件，定量分析冬小麦干旱与气象干旱的关系和重现期频 率，但仍然存在以下问题需进一步讨论：

（1）干旱指数构建：CWDI指数主要考虑作物不同生长阶段的蒸散发过程，利用 Penman-Monteith公式计算 ${ }^{[31]}$ 冬小麦不同生育阶段的参考作物蒸散量，能够反映农作物关 键生长期的干旱特征，但针对不同生育阶段的水分亏缺状态选择固定的权重系数，无法 准确反映不同地区农作物生长的实际干旱情况; 气象干旱使用 $M$ 指数表征, 从降水和蒸 散发的比例关系考虑，能够反应地区气象干旱程度，但未来应从大气一气候一土壤的水 分循环过程各个要素条件来考虑地区气象干旱特征。

（2）干旱事件识别：选取游程理论来识别农业干旱与气象干旱事件，从干旱事件识 别的准确度上来看, 可以在《中国气象灾害大典》（河南卷、安徽卷）和《中国气象灾害 年鉴》 ${ }^{[25-27]}$ 中得到验证。但在 30 场主要干旱事件的识别中，第 10 、第 11 和第 20 场干旱事 件农业干旱较气象干旱发生时间更早（表3），干旱发生的时间顺序上有悖于常理，可能 受到了阈值选取的主观性影响。 $\mathrm{Y}_{0}$ 干旱阈值采取试错法并结合专家意见，根据农业干旱 与气象干旱等级阈值差值作为 $Y_{1}$ 与 $Y_{2}$ 干旱阈值, 据此识别的干旱事件准确度达到 $90 \%$ 左 
右，未来可以选择更加科学的方法确定干旱事件阈值，减少人为主观因素识别干旱事件 造成的误差。

(3) 干旱时空特征：分析农业干旱与气象干旱的年际特征, 计算 60 个站点的 CWDI 和 $M$ 指数，基于分位数模型发现农业干旱在干旱发生的频率和强度明显高于气象干旱， 是由于农业干旱较气象干旱存在时滞，并延续干旱状态到下一时段，而气象干旱的旱情 减轻无法及时缓解农业干旱，农业干旱对气象干旱或非气象干旱皆存在时滞，未来需就 农业干旱对气象干旱的响应和时滞特征做进一步研究。分析农业干旱与气象干旱的空间 特征, 农业干旱旱情相较于气象干旱而言, 空间分布上更加广，而地区内的冬小麦从冬 前生长期到返青抽穗期，同一个干旱等级的农业干旱在空间上存在西北向东南的分布， 而气象干旱在全生育阶段同一干旱等级均为纬向分布，两种干旱空间分布存在差异。由 于淮河蛙埠闸以上地区自西北向东南的地形走势，造成地区灌溉条件存在差异，进而影 响地区农业干旱同一干旱等级呈现出自西北向东南的分布特征; 气象干旱在冬小麦不同 生育阶段同一干旱等级存在较为明显的纬向分布，与地区内的气候特征和水热条件分布 特点密不可分 ${ }^{[40]}$ 。

（4）干旱历时和烈度重现期频率及其关系：计算农业干早历时与烈度重现期，以及 气象干旱的历时及烈度重现期，构建三参数对数函数反映干旱烈度与干早历时的响应关 系，通过了显著性检验，确定未来干旱烈度对干旱历时响应的定量关系，但干旱历时和 干旱烈度的实际值与模拟值相对误差较大，干旱历时模拟值与实际值、干旱烈度模拟值 与实际值分别仅有 5 场和 2 场干旱事件的相对误差小于 $10 \%$ ，未来需构建更加准确模拟干 旱历时与干旱烈度的响应关系，减少模拟值与实际值的相对误差。

\section{参考文献(References):}

[1] 季定民, 张勃, 王东, 等. 甘肃河东玉米种植区春夏气象干旱时空变化特征及其与环流因子关系. 自然资源学报, 2015, 30(9): 1547-1559. [JI D M, ZHANG B, WANG D, et al. Spatio-temporal variation characteristics of spring and summer meteorological drought and its relationship with circulation factors in Hedong maize planting areas of Gansu province. Journal of Natural Resources, 2015, 30(9): 1547-1559.]

[2] PING H, PENG X W, SHU Y Z, et al. Drought forecasting based on the remote sensing data using ARIMA models. Mathematical and Computer Modelling, 2010, 51(11-12): 1398-1403.

[3] American Meteorological Society. Meteorological drought-policy statement. Bulletin of the American Meteorological Society, 1997, 78: 847-849.

[4] 姚玉璧, 张存杰, 邓振镛, 等. 气象、农业干旱指标综述. 干旱地区农业研究, 2007, 25(1): 185-189, 211. [YAO Y B, ZHANG C J, DENG Z Y, et al. Overview of meteorological and agricultural drought indices. Agricultural Research in the Arid Areas, 2007, 25(1): 185-189, 211.]

[5] 刘宪锋, 朱秀芳, 潘耀忠, 等. 农业干旱监测研究进展与展望. 地理学报, 2015, 70(11): 1835-1848. [LIU X F, ZHU X F, PAN Y Z, et al. Agricultural drought monitor: Progress, challenges and prospect, Acta Geographica Sinica, 2015, 70 (11): 1835-1848.]

[6] 李栋梁, 彭素琴. 中国西部降水资源的稳定性研究. 应用气象学报, 1992, 3(4): 451-458. [LI D L, PENG S Q. Stability of precipitation resources in western China. Quarterly Journal of Applied Meteorology, 1992, 3(4): 451-458.]

[7] HOLZMAN B G, THOM H C S. The La Porte precipitation anomaly. Bulletin of the American Meteorological Society, 1970, 51(4): 335-337.

[8] 樊高峰, 苗长明, 毛裕定. 干旱指标及其在浙江省干旱监测分析中的应用. 气象, 2006, 32(2): 70-74. [FAN G F, MIAO C M, MAO Y D. Application of drought indexes to dryness assessment in Zhejiang province. Meteorological Monthly, 2006, 32(2): 70-74.] 
[9] 钱正安, 吴统文, 宋敏红, 等. 干旱灾害和我国西北干旱气候的研究进展及问题. 地球科学进展, 2001, 16(1): 28-38. [QIAN Z A, WU T W, SONG M H, et al. Arid disaster and advances in arid climate researches over Northwest China. Advances in Earth Science, 2001, 16(1): 28-38.]

[10] 黄晚华, 杨晓光, 李茂松, 等. 基于标准化降水指数的中国南方季节性干旱近 58 a 演变特征. 农业工程学报, 2010, 26 (7): 50-59. [HUANG W H, YANG X G, LI M S, et al. Evolution characteristics of seasonal drought in the south of China during the past 58 years based on Standardized Precipitation Index. Transactions of the CSAE, 2010, 26(7): 50-59.]

[11] PAUlO A, PEREIRA L. Prediction of SPI drought class transitions using Markov Chains. Water Resource Management, 2007, 2(1): 1813-1827.

[12] VICENTE-SERRANO S M, BEGUERA S, LPEZ-MORENO J I. A Multiscalar drought index sensitive to global warming: The Standardized Precipitation Evapotranspiration Index. Journal of Climate, 2010, 23(7): 1696-1718.

[13] 唐敏, 张勃, 张耀宗, 等. 基于 SPEI 和 SPI 指数的青海省东部农业区春夏气象干旱特征的评估. 自然资源学报, 2017, 32(6): 1029-1042. [TANG M, ZHANG B, ZHANG Y Z, et al. Assessment of spring and summer meteorological droughts based on SPEI and SPI in eastern agricultural region of Qinghai province. Journal of Natural Resources, 2017, 32(6): 1029-1042.]

[14] BEGUERIA S, VICENTE-SERRANO S M, REIG F, et al. Standardized Precipitation Evapotranspiration Index (SPEI) revisited: Parameter fitting, evapotranspiration models, tools, datasets and drought monitoring. International Journal of Climatology, 2013, 34(10): 3001-3023.

[15] 张晶晶, 陈爽, 赵昕奕. 近 50年中国气温变化的区域差异及其与全球气候变化的联系. 干旱区资源与环境, 2006, 20 (4): 1-6. [ZHANG J J, CHEN S, ZHAO X Y. Spatial divergency of temperature change during 1951-2000 in China and its correlation with global climate change. Journal of Arid Land Resources and Environment, 2006, 20(4): 1-6.]

[16] QIAN S, FU Y, PAN F F. Climate change tendency and grassland vegetation response during the growth season in Three-River Source Region. Science China Earth Sciences, 2010, 53(10): 1506-1512.

[17] 高晓容. 东北地区玉米主要气象灾害风险评估研究. 南京: 南京信息工程大学, 2012. [GAO X R. Study on the risk assessment of the main meteorological disasters for maize in Northeast China. Nanjing: Nanjing University of Information Science \& Technology, 2012.]

[18] 李学文, 高超, 尹周祥. 淮河流域蚌埠闸以上地区夏玉米生长水分关键期干旱致灾降水阈值. 水土保持研究, 2018, 25(5): 162-169, 178. [LI X W, GAO C, YIN Z X. Precipitation threshold of drought for maize above the Bengbu Sluice in the Huaihe River Basin, China. Research of Soil Water Conservation, 2018, 25(5): 162-169, 178.]

[19] GAO C, LI X W, SUN Y W, et al. Water requirement of summer maize at different growth stages and the spatiotemporal characteristics of agricultural drought in the Huaihe River Basin, China. Theoretical and Applied Climatology, 2019, 136 (3-4): 1289-1302.

[20] GAO C, LI X W. Precipitation thresholds of drought disaster for maize in areas in front of Bengbu Sluice, Huaihe River Basin, China. Water, 2018, 10(10): 1-18.

[21] 袁文平, 周广胜. 干旱指标的理论分析与研究展望. 地球科学进展, 2004, 19(6): 982-991. [YUAN W P, ZHOU G S. Theoratical study and research prospect on drought indices. Advances in Earth Science, 2004, 19(6): 982-991.]

[22] 高超, 尹周祥, 许莹. 淮河流域冬小麦主要生育期旱涝时空特征及对产量的影响. 农业工程学报, 2017, 33(22): 103111. [GAO C, YIN Z X, XU Y. Space-time characteristics of drought and flood in main growing periods of winter wheat in Huaihe River Basin and its impact on yield. Transactions of the CSAE, 2017, 33(22): 103-111.]

[23] 徐新创, 葛全胜, 郑景云, 等. 区域农业干旱风险评估研究: 以中国西南地区为例. 地理科学进展, 2011, 30(7): 883890. [XU X C, GE Q S, ZHENG J Y, et al. Drought risk assessment on regional agriculture: A case in Southwest China. Progress in Geography, 2011, 30(7): 883-890.]

[24] 刘宗元, 张建平, 罗红霞, 等. 基于农业干旱参考指数的西南地区玉米干旱时空变化分析. 农业工程学报, 2014, 30 (2): 105-115. [LIU Z Y, ZHANG J P, LUO H X, et al. Temporal and spatial distribution of maize drought in southwest of China based on agricultural reference index for drought. Transactions of the CSAE, 2014, 30(2): 105-115.]

[25] 庞天荷. 中国气象灾害大典: 河南卷. 北京: 气象出版社, 2005. [PANG T H. Encyclopaedia of China Meteorological Disasters: Henan Volume. Beijing: China Meteorological Press, 2005.]

[26] 中国气象局. 中国气象灾害年鉴. 北京: 气象出版社, 2011. [China Meteorological Administration. China Meteorologi- 
cal Disaster Yearbook. Beijing: China Meteorological Press, 2011.]

[27] 中国气象局. 中国气象灾害年鉴. 北京: 气象出版社, 2012. [China Meteorological Administration. China Meteorological Disaster Yearbook. Beijing: China Meteorological Press, 2012.]

[28] 董秋婷, 李茂松, 刘江, 等. 近 50 年东北地区春玉米干旱的时空演变特征. 自然灾害学报, 2011, 20(4): 52-59. [DONG Q T, LI M S, LIU J, et al. Spatio-temporal evolution characteristics of drought of spring maize in Northeast China in recent 50 years. Journal of Natural Disasters, 2011, 20(4): 52-59.]

[29] 曹兴, 万瑜, 崔玉玲, 等. 中天山北坡近 30年相对湿润指数变化趋势分析. 干旱地区农业研究, 2013, 31(3): $244-251$. [CAO X, WAN Y, CUI Y L, et al. Analysis on change tendency of relative moisture index in northern piedmont of Middle Tianshan Mountain over recent 30 years. Agricultural Research in the Arid Areas, 2013, 31(3): 244-251.]

[30] 中华人民共和国国家质量监督检验检疫总局国家标准化委员会. 冬小麦干旱等级, 2009. [Standardization Administration, General Administration of Quality Supervision. Inspection and Quarantine of the People's Republic of China. Grade of Winter Wheat Drought, 2009.]

[31] Beven K. A sensitivity analysis of the Penman- Monteith actual evapotranspiration estimates. Journal of Hydrology, 1979, 44(3-4): 169-190.

[32] YEVJEVICH V M. An objective approach to definitions and investigations of continental hydrologic droughts. Hydrology Papers: No.23, Colorado State University, Fort Collins, 1967.

[33] 李明, 柴旭荣, 王贵文, 等. 长江中下游地区气象干旱特征. 自然资源学报, 2019, 34(2): 374-384. [LI M, CHAI X R, WANG G W, et al. Research on meteorological drought in the middle and lower reaches of the Yangtze River. Journal of Natural Resources, 2019, 34(2): 374-384.]

[34] 周玉良, 袁潇晨, 金菊良, 等. 基于 Copula 的区域水文干旱频率分析. 地理科学, 2011, 31(11): 1383-1388. [ZHOU Y L, YUAN X C, JIN J L, et al. Regional hydrological drought frequency based on Copulas. Scientia Geographica Sinica, 2011, 31(11): 1383-1388.]

[35] 尹周祥, 高超, 李学文, 等. 淮河上游冬小麦生长关键期旱涝灾害阈值研究. 灌溉排水学报, 2017, 36(7): 100-107. [YIN Z X, GAO C, LI X W, et al. Threshold drought and flooding at critical growth period of winter wheat in the upper reach of Huai River. Journal of Irrigation and Drainage, 2017, 36(7): 100-107.]

[36] 刘维哲, 唐溧, 王西琴, 等. 农业灌溉用水经济价值及其影响因素: 基于剩余价值法和陕西关中地区农户调研数据. 自然资源学报, 2019, 34(3): 553-562. [LIU W Z, TANG L, WANG X Q, et al. Estimating economic value of irrigation water and analysis of influencing factors: A case study based on residual value method and farmers data in Guanzhong area of Shaanxi. Journal of Natural Resources, 2019, 34(3): 553-562.]

[37] MEISNER A, ROUSK J, BÅTH E. Prolonged drought changes the bacterial growth response to rewetting. Soil Biology and Biochemistry, 2015, 88: 314-322.

[38] 张宇亮, 蒋尚明, 金菊良, 等. 基于区域农业用水量的干旱重现期计算方法. 水科学进展, 2017, (5): 53-63. [ZHANG Y L, JIANG S M, JIN J L, et al. Computational methods of drought return periods based on the regional agricultural water consumption, Advances in Water Science, 2017, (5): 53-63.]

[39] 吴冬平, 杨光, 金菊良, 等. 干旱频率计算的简化方法探讨: 以齐齐哈尔市为例. 自然灾害学报, 2015, 34(6): 201208. [WU D P, YANG G, JIN J L, et al. On simplified method for calculation of drought frequency: A case study on Qigihar city. Journal of Natural Disasters, 2015, 34(6): 201-208.]

[40] 许芗, 马晓群, 王晓东, 等. 淮河流域冬小麦水分亏缺时空变化特征分析. 地理科学, 2013, 33(9): 1138-1144. [XU Y, MA X Q, WANG X D, et al. Analysis of spatial and temporal variation characteristics of winter wheat water deficiency in Huaihe River Basin. Scientia Geographica Sinica, 2013, 33(9): 1138-1144.] 


\title{
Agricultural drought and its association with meteorological drought:
}

\section{A case study of the Huaihe River Basin above the Bengbu Sluice, China}

\author{
LUO Gang ${ }^{1}$, RUAN Tian², CHEN Cai ${ }^{1}$, GAO Chao ${ }^{1}$, LI Peng ${ }^{3}$, \\ MA Song-gen ${ }^{3}$, LI He-li, WANG Huan ${ }^{3}$ \\ (1. Department of Geography \& Spatial Information Techniques, Ningbo University, Ningbo 315211, Zhejiang, \\ China; 2. School of Geography and Tourism, Anhui Normal University, Wuhu 241000, Anhui, China; \\ 3. Zhumadian Hydrology and Water Resources Survey Bureau, Zhumadian 450003, Henan, China)
}

\begin{abstract}
Based on the meteorological data of 60 stations above the Bengbu Sluice of Huaihe River from 1961 to 2015, crop water deficit index (CWDI) and relative moisture index $(M)$ were calculated. By taking winter wheat drought as the representative of agricultural drought, the temporal and spatial characteristics of winter wheat drought and meteorological drought during the growth period were analyzed. The duration, severity and frequency of 30 major drought events were identified through the run theory, and the correlation between agricultural drought and meteorological drought was studied. The results showed that: (1) In terms of time, the proportion of agricultural drought in winter wheat growth period was higher than that of meteorological drought, and the years with the largest interannual difference occurred in the pre-winter growth period; (2) In terms of space, the winter wheat drought and meteorological drought in the whole growth period and each growth period were distributed by zonal mode structure, and the drought gradually increases from south to north. More than $75 \%$ of the drought of winter wheat occurs from over-wintering period to filling and mature period, while meteorological drought only occurred during over-wintering period; (3) Winter wheat drought was delayed compared with meteorological drought, and its intensity was greater than that of meteorological drought. The average duration was 18.8 dekad and 17.3 dekad, respectively, and the average severity was 12.2 and 9.9, respectively; (4) When the duration of meteorological drought reached 1.28 dekad or the drought severity reached 3.35, the drought of winter wheat will be triggered, and the frequency of the duration and severity return period of winter wheat drought was greater than that of meteorological drought. Agricultural drought has a longer duration, greater frequency and greater severity than meteorological drought and meteorological drought aggravates agricultural drought.
\end{abstract}

Keywords: agricultural drought; meteorological drought; run theory; return period 